\title{
The differences of Slovenian and Italian daily practices experienced in the first wave of covid-19 pandemic
}

\author{
Saša Pišot ${ }^{*}$, Boštjan Šimunič ${ }^{2}$, Ambra Gentile ${ }^{2}$, Antonino Bianco ${ }^{2}$, Gianluca Lo Coco ${ }^{2}$, Rado Pišot ${ }^{1}$, \\ Patrik Drid ${ }^{3}$ and Ivana Milovanović ${ }^{3}$
}

\begin{abstract}
Background: The COVID-19 pandemic situation with the lockdown of public life caused serious changes in people's everyday practices. The study evaluates the differences between Slovenia and Italy in health-related everyday practices induced by the restrictive measures during first wave of the COVID-19 pandemic.

Methods: The cross-sectional cohort study examined changes through an online survey conducted in nine European countries from April 15-28, 2020. The survey included questions from a simple activity inventory questionnaire (SIMPAQ), the European Health Interview Survey, and some other questions. To compare difference in changes between European countries we examined Italy with severe and its neighbour country Slovenia with low incidence and victims of COVID-19 epidemic. 956 valid responses from Italy ( $N=511 ; 50 \%$ males) and Slovenia $(N=445 ; 26 \%$ males) were investigated.
\end{abstract}

Results: During the survey, there was a 4.7-fold higher incidence and 12.1-fold more deaths (per 100,000) in Italy than in Slovenia. Barring periods and measures were similar, the latter more stringent in Italy. We found more changes in Italy than in Slovenia: physical inactivity increased (Italy: +65\% vs. Slovenia: $+21 \% ; p<0.001$ ), walking time decreased (Italy: -68\% vs. Slovenia: $-4.4 \%$; $p<0.001$ ); physical work increased by 38\% in Slovenia $(p<0.001)$, and recreation time decreased by $37 \%$ in Italy $(p<0.001)$. Italians reported a decrease in quality of general health, fitness level, psychological well-being, quality of life and care for own health $(p<0.001)$; Slovenians showed a decline in psychological well-being and quality of life $(p<0.001)$ but generally had a higher concern for their own health $(p=0.005)$. In pooled participants, changes in eating habits (meal size and consumption of unhealthy food), age and physical inactivity were positively correlated with increases in body mass, while changes in general well-being and concern for health were negatively correlated.

Conclusion: The study shows that the negative impact of COVID -19 measures is greater in Italy where the pandemic COVID -19 was more prevalent than in Slovenia with low prevalence. Additional consideration should be given to the negative impact of COVID-19 measures on some health-related lifestyle variables when implementing further measures to mitigate the COVID-19 pandemic.

Keywords: Physical activity and inactivity behaviour, Dietary/eating habits, Well-being, Home confinement, COVID19 pandemic measures

\footnotetext{
*Correspondence: sasa.pisot@zrs-kp.si

${ }^{1}$ Institute for Kinesiology Research, Science and Research Centre Koper,

Koper, Slovenia

Full list of author information is available at the end of the article
} 


\section{Introduction}

Temporal rhythms are actively reproduced in everyday life and are understood as accumulations of everyday practices, as performances of coordinating and stabilizing relations between practices [1]. In everyday life, we need to prioritize where routines, habits, and practices are autonomous in order to manage and bind our lives. The rhythms of life give us a sense of security and keep us in constant relationships-this is most evident when our routines and habits are disrupted [2]. The state of COronaVIrus Infectious Disease 2019 (COVID-19) pandemic measures as such a disruptive circumstance, affecting daily practices and disrupting "elementary" routines in such a way that it had a profound effect on overall social integration $[3,4]$.

In the cross-sectional cohort study in nine European countries, we faced two different situations. Slovenia (SLO) borders Italy (ITA), where citizens witnessed a very serious situation in the first wave of the pandemic in the province of Bergamo, while SLO, in contrast, experienced a "milder" situation as other eastern countries (Slovakia, Croatia and Serbia). This intrigued us to find out how the more serious situation and the higher number of victims, and the resulting severity of the measures taken by Italy compared to Slovenia, affected some lifestyle variables.

The first confirmed case of COVID-19 in ITA was on January 31, 2020, and when further cases emerged in Codogno (Milan), the ITA government imposed a quarantine on infected individuals, their contacts, and those returning from China, on February 21, 2020. Subsequently stricter measures were imposed for northern ITA on March 8, 2020 "Declaration of Red Zones" and a total lockdown on public life "\#stayathome regulation" on March 11, 2020. From March 20, 2020 was forbidden to enter in public parks, playground areas, and to play outside. Sports activities were only allowed near residences [5].

The Slovenian COVID-19 experience has been different, emerging about 20 days later with lower incidence and fewer victims as well as milder movement restrictions. After the first case of COVID-19 was confirmed on March 4, 2020 and due to the very difficult situation in Bergamo province (ITA), the SLO government passed the Decree on the Declaration of Contagious Disease SARSCov-2 (COVID-19) on March 12, 2020 declaring the first measures: shut down of kindergartens, schools, universities, and from March 16 of open playgrounds, sport parks, sport training camps, and public transportation. As of March 20, 2020 it was forbidden to enter public areas and from March 30, 2020 mobility was only allowed within the municipal borders of residential cities [6].
SLO measures were initiated later, otherwise comparable to ITA, except for the restriction living the residential and to be physically active, which were stricter in ITA [7]. However, by April 28, 2020, there were 142 times more COVID-19 cases (per capita: 4.9 times) and 325 times more COVID related deaths (per capita: 11.2 times) in ITA than in SLO, and this fact had a significant impact on stricter adherence to restrictions on ITA (Fig. 1) and changed people's everyday life activities more.

It is well known that restrictive measures due to COVID-19 impacted people's everyday habits [3, 4], however, it is not known how these restrictions impacted two neighbouring countries (SLO and ITA), where COVID19 restrictive measures lasted for two months with a much worse epidemiological outcome in ITA (especially Northern) than in SLO. Specifically, the quarantine was considered one of the most helpful measures to contain the infection, but on the other hand limited people's movement outdoors and reduced physical activity mostly to the domestic area.

Because the study examined everyday practices, the research focused on practices that are important to maintain and enhance health, such as domains of physical activity (PA) and, dietary/eating habits that reflect an individual's overall well-being [8]. As smoking and alcohol consumption have been found to increase during the COVID-19 pandemic in some EU countries (Poland and Belgium) $[9,10]$, these two health-related risk behaviours have also been examined. The positive effects of PA habits on quality of life (QoL) have been demonstrated many times. Not only in active older patients in physical and psychological QoL [11] but also in younger age groups [12], and in chronic patients [13]. PA improves health related QoL in cancer patients [14] and patients with diabetes mellitus [15], where those who met weekly moderate and vigorous PA recommendations reported better physical functioning and were more likely to maintain their physical and overall QoL over time [8]. Covid19 pandemic studies also suggest an impact on dietary behaviour $[4,16]$. Feeling forced to stay indoors because of the lockdown of public life or quarantine could be considered a psychological risk factor for consuming a higher quantitative intake and/or poorer quality (unhealthier) food compared to normal living conditions [17]. The pandemic period could therefore cause changes in dietary habits and energy balance proportions, usually leading to weight gain [17], which is also reflected in QoL.

The aim of the study was to examine the consequences on selected health-related lifestyle variables during COVID-19 restrictions in two neighbouring countries with very different COVID-19 epidemiological impact during COVID-19 first pandemic wave. In light of this, we hypothesized that changes of everyday life practices, 


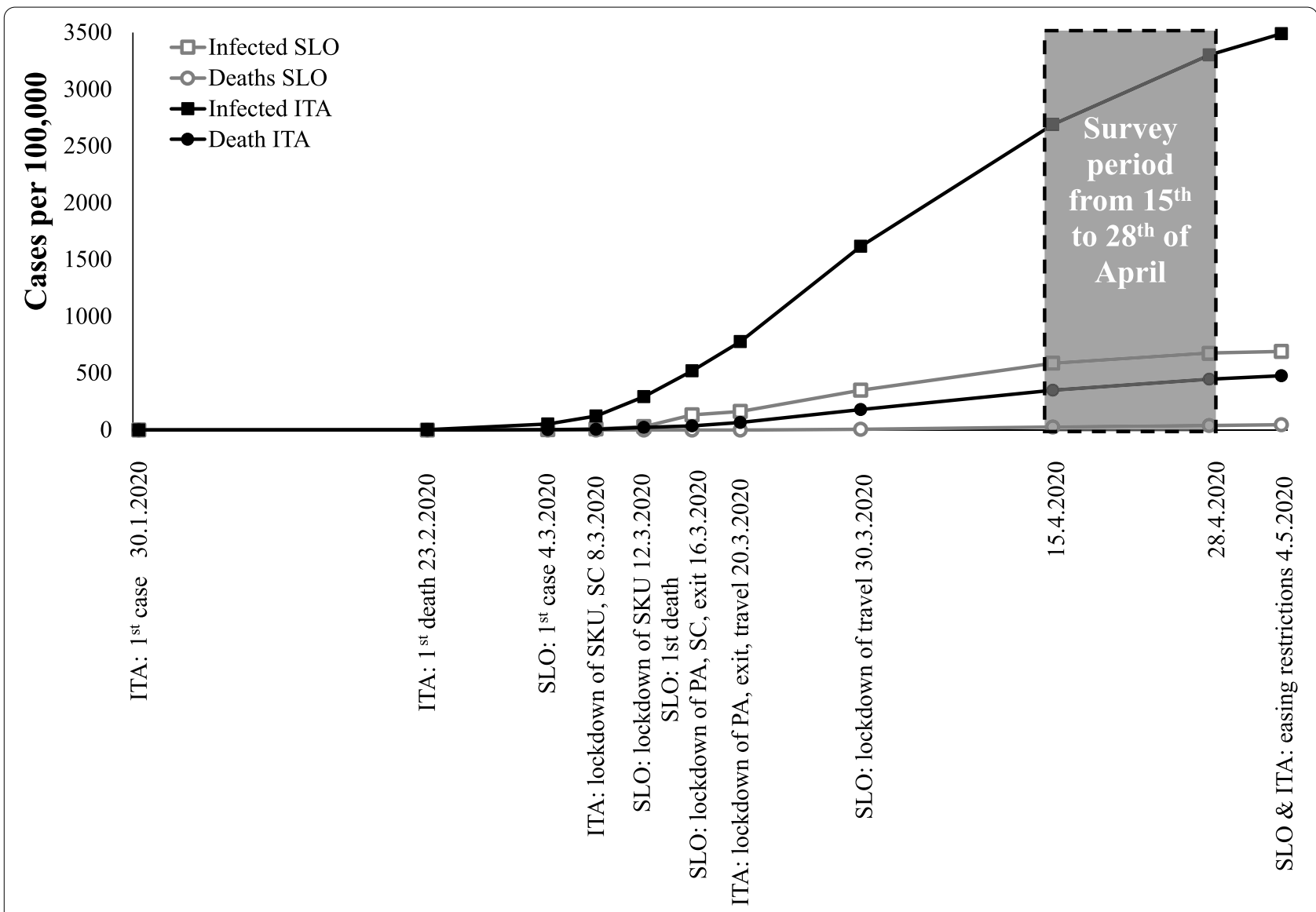

Fig. 1 A timeline of restrictions with COVID-19 cases and death in the year 2020 for Italy and Slovenia

such as PA habits, diet (weight gain), health related risk behaviours (alcohol consumption and smoking) and quality of life (QoL) domains were higher in ITA than in SLO due to restrictive government interventions and the severity of COVID-19 epidemiological impact in ITA.

\section{Methods}

\section{Participants}

Altogether 956 Slovenian and Italian respondents were taken for this analysis. See Table 1 for detailed description of the study sample. All respondents were older than 18 years. Informed consent was obtained from all participants on the first page of survey. Specifically, after reading the description of the survey and when they progressed to the first survey question, they marked their consent to participate in the study. See detailed description in Ethics approval and consent to participate. The study was ethically approved by the Faculty of Sport and Physical Education at University of Novi Sad, Serbia (Decision No. 46-06-02/20).

\section{Research design}

This study is a part of a larger cross-sectional cohort study of everyday life practices in the time of the COVID19 pandemic (ELP-COVID-19 survey) [3, 18] conducted in nine European countries, besides ITA and SLO, also Bosnia and Herzegovina, Croatia, Greece, Kosovo, Serbia, Slovakia, and Spain, from April 15 to 28 2020, with the aim to identify the changes of everyday life practices and routines during the period before (baseline) and during the COVID-19 pandemic measures. ELP (Everyday life praxis) COVID-19 (ELP COVID-19) consortium of six partners from Science and Research Centre Koper (Slovenia), Faculties of sport, University of Novi Sad (Serbia), University of Palermo (Italy), University of Zagreb (Croatia), University of Prešov (Slovakia), University of Cadiz (Spain) has been established for this purpose [3].

\section{The online questionnaire}

The questionnaire "Everyday life in the time of COVID-19 pandemic restriction" (ELP COVID-19 study) was made for the purpose of the research and consisted of whole or/and the adapted parts of validated questionnaires: 
Table 1 Sample characteristics

\begin{tabular}{|c|c|c|c|c|}
\hline & \multicolumn{2}{|c|}{ Slovenia } & \multicolumn{2}{|c|}{ Italy } \\
\hline & $N$ & $\%$ & $N$ & $\%$ \\
\hline \multicolumn{5}{|l|}{ Sex } \\
\hline Males & 117 & 26.3 & 258 & 50.5 \\
\hline Females & 328 & 73.7 & 253 & 49.5 \\
\hline \multicolumn{5}{|l|}{ Age } \\
\hline$\leq 20$ years & 23 & 5.2 & 58 & 11.3 \\
\hline $21-30$ years & 96 & 21.6 & 301 & 58.9 \\
\hline $31-40$ years & 89 & 20.0 & 75 & 14.7 \\
\hline $41-50$ years & 95 & 21.3 & 35 & 6.8 \\
\hline $51-60$ years & 85 & 19.1 & 31 & 6.1 \\
\hline $61-70$ years & 47 & 10.6 & 11 & 2.2 \\
\hline $71-80$ years & 9 & 2.0 & 0 & 0 \\
\hline$\geq 81$ years & 1 & 0.2 & 0 & 0 \\
\hline \multicolumn{5}{|l|}{ Level of education } \\
\hline Basic (elementary) education or less & 5 & 1.1 & 10 & 2.0 \\
\hline Vocational training & 23 & 5.2 & 4 & 0.8 \\
\hline Secondary education & 133 & 29.9 & 202 & 39.5 \\
\hline Higher professional education & 47 & 10.5 & 11 & 2.2 \\
\hline Higher professional or university education & 148 & 33.3 & 142 & 27.8 \\
\hline Master's Degree (Specialist in HE) & 46 & 10.3 & 127 & 24.8 \\
\hline Doctoral degree (PhD) & 43 & 9.7 & 15 & 2.9 \\
\hline
\end{tabular}

SIMPAQ - Simple Physical Activity Questionnaire [19] to collect data on sleeping time, PA, inactivity time as time before COVID-19 pandemic (BDC) and time during COVID- 19 pandemic measures (during); adapted part of EHIS European Health Interview Survey [20] for scales to assess eating habits and indicators of quality of life. We assessed the change in body mass (in $\mathrm{kg}$ ) in those using a body mass scale regularly. For those who did not, we assessed the change of body mass using a 5-point Likert scale (1- deceased a lot, 2- decreased a little, 3- stayed the same, 4- increased a little, 5- increased a lot). Additionally, changes in quality and quantity of eating and other health-related risk habits (alcohol and tobacco use) were also assessed by 5 -point (Likert) scale (1-much less, 2-less 3- the same, 4- a little more, 5- much more, another option 6- can't estimate and 7- not applicable (for those who do not consume alcohol and smoke).

The open ended on-line survey consists of a total of 26 questions and was translated from English into eight different languages of participating countries, including Slovene and Italian.

The survey was based on a rendom sample, in which consortium researchers invited participants aged 18 and older who could be reached through a variety of means: personal email addresses, official websites of partner organizations, local online newspapers, etc. Prior the fielding the survey, the electronic questionnaire was tested in all participating countries by the research team in all languages. This included also checking the linguistic and formal suitability of the questionnaire and making any necessary adjustments. The survey was open from 15 to 28 April 2020.

The survey was formed in 1KA, an open-source application that enables services for online surveys, developed by the Centre for Social Informatics, at the Faculty of Social Sciences, University of Ljubljana, Slovenia (https://www.1ka.si/d/en/about/general-description). Data collection and analyses followed the General Data Protection Regulation (GDPR). Participation in the survey was voluntary, visitors of the first page can decide to participate after the survey announcement. Additionally, respondents had the option to opt out of the questionnaire at any point prior to the submission process. Respondents were able to review and change their answers using the back button. Most of the questions in the survey were mandatory, a check for completeness after submitting the questionnaire was possible and mandatory items were highlighted.

\section{Statistics}

Only surveys with completed mandatory questions were taken into analysis. The SPSS (version 26.0, IBM, USA) was used for data analysis. All data were presented as mean (standard deviation) values and were analysed separately for SLO and ITA regarding the collected data for the times before and during COVID-19 pandemic measures. Normal distribution (Histogram, Q-Q-plot, Skewness, Kurtosis, Shapiro-Wilk test) and homogeneity of variance (Levene test) were checked and met. The multivariate difference in all 14 everyday practices variables were tested by multivariate Hotelling's $T^{2}$ test [21], while differences in each variable was tested by 2-way ANOVA (time, country) with age and sex differences between countries as a covariates. Statistical significance was set at $p<0.05$. Where changes in baseline values (before) were identified, an analysis of covariance (ANCOVA), with baseline values as additional covariate, was used to determine differences in changes during COVID-19 restrictions. Identification of significant predictors of body mass changes in the subsample of those using a body mass scale regularly $(N=548)$ was made by a Multiple Linear Regression, where predictors passed non-multicollinearity assumptions (variance inflation factor $<2$ ). A subsample was used to assure interval scale of dependent variable (body mass change). Additionally, we presented frequency analysis of gaining weight (for a subsample of those who did not monitoring weight, $N=408$ ), changes in eating habits, alcohol consumption 
and smoking in Fig. 3. For that purpose, only subjects that responded on a 5-point (Likert) scale: 1-much less, 2-less, 3-the same, 4-little more, and 5-much more, were analysed: While those that indicated 6-cannot estimate or 7-not applicable were excluded. In each analysis (of practices) a Bonferroni correction of $\mathrm{p}$-value was used.

\section{Results}

\section{Description of the study sample}

Respondents answered the survey over a period of 33.9 (6.0) days after pandemic measures were declared by the state government in SLO and 44.9 (6.4) days in ITA, when most changes could become latent. The participation rate was $17 \%$ in SLO and 19\% in ITA while the completion rate reached $31 \%$ in SLO and $73 \%$ in ITA. The sample (Table 1) consisted of 445 SLO (26.3\% males, aged $42.1 \pm 14.9$ years) and 511 ITA respondents $(50.5 \%$ males, aged 29.6 \pm 11.0 years). Most of the respondents were between 21-30 years old in ITA and 21-60 years in SLO, respectively, and representing the active population (employed, self-employed) (SLO 67\%, ITA 46.5\%) and students (SLO 16.4\%, ITA 40.5\%). Most respondents had a higher level of education and especially in the ITA sample prevail younger population, as the primary dissemination channel of the online survey was among students and university staff.

Baseline physical inactivity differed between the countries; therefore, we controlled different baseline values using ANCOVA, and confirmed greater changes in ITA than in SLO (Fig. 2). Specifically, physical inactivity increased (ITA $65 \%$ vs. SLO $21 \%$; $p<0.001$ ); physical work increased only in SLO by $38 \%(p<0.001)$; walking time decreased (ITA $68 \%$ vs. SLO $4.4 \%$; $p<0.001$ ); however, sport recreation time decreased in ITA by $37 \%$ $(p<0.001)$ but increased in SLO by $9.7 \%(p<0.001)$.

Figure 3 presents changes in nutrition during COVID19 restrictions in ITA resulting in an increase of body mass, meal regularity and meal sizes, while alcohol consumption and smoking decreased $(p<0.001)$. Similarly, in SLO COVID-19 restrictions increased body mass and meal regularity while alcohol consumption
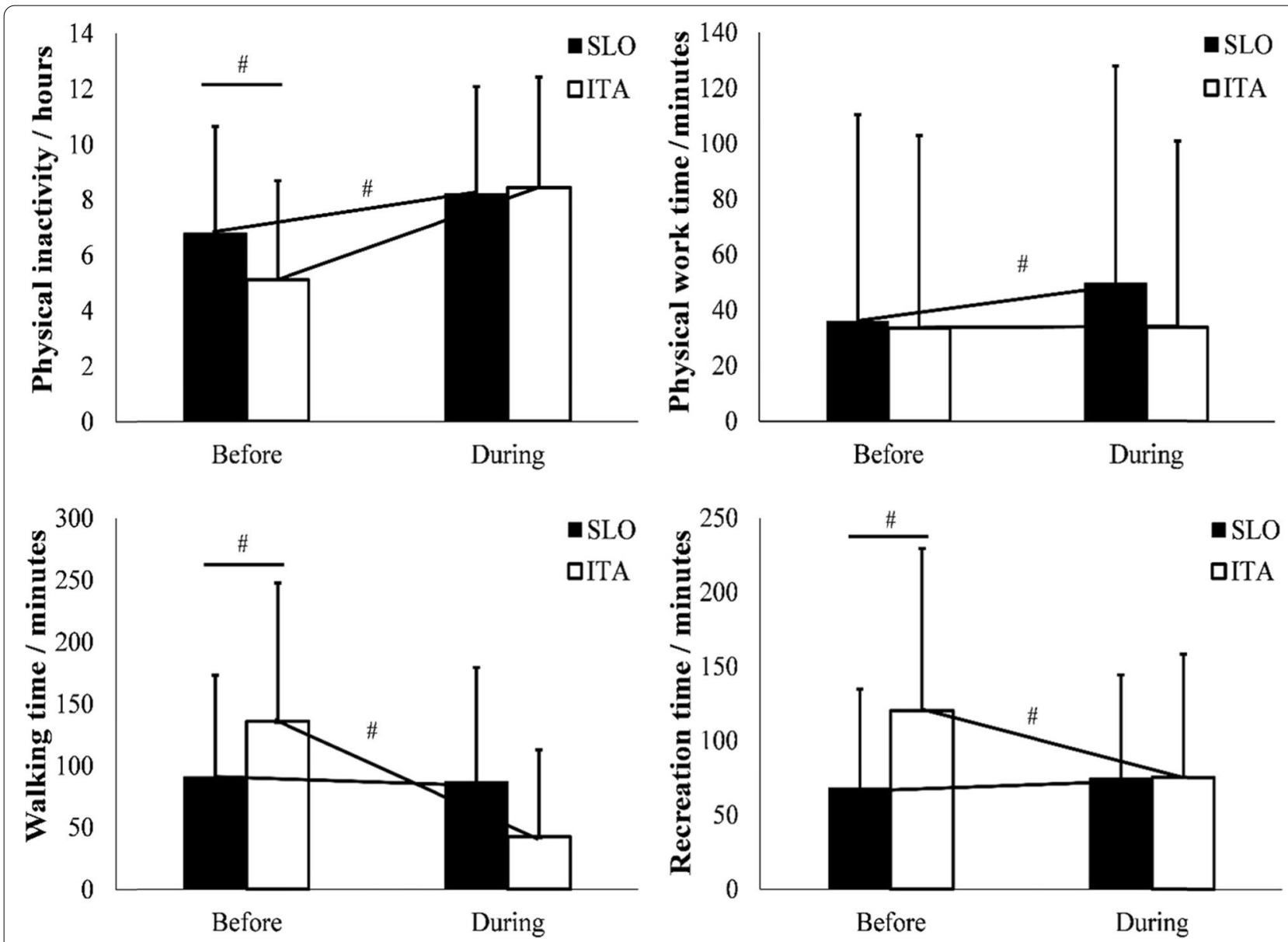

Fig. 2 Physical inactivity, Physical work, Walking time and Physical activity as recreation time before and during COVID-19 measures 


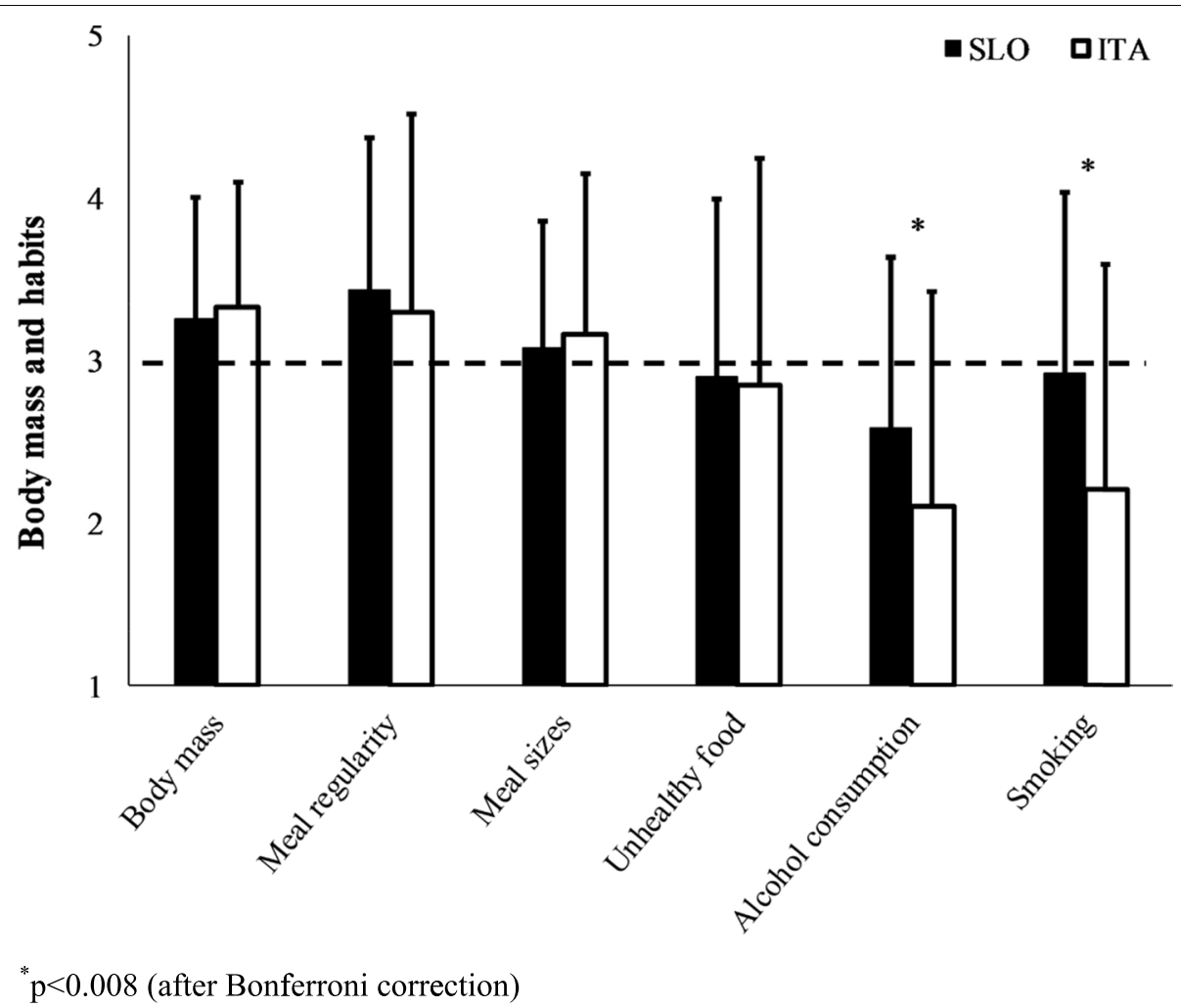

Fig. 3 Likert scale values of body mass, eating habits, alcohol consumption, and smoking changes (increases $>3$ or decreases $<3$ ) during COVID-19 restrictions in Slovenia (SLO) and Italy (ITA)

decreased $(p<0.001)$. The difference in the magnitude of change between the two countries was found in alcohol consumption decreasing more in ITA than in SLO (2.11 \pm 1.32 vs. $2.59 \pm 1.04 ; p=0.001)$ and in smoking, which decreased only in ITA, while in SLO it remained unchanged $(2.21 \pm 1.39$ vs. $2.93 \pm 1.11 ; p<0.001)$.

Figure 4 presents changes in self-reported wellbeing during COVID-19 restrictions. ITA reported worse general health status, fitness levels, psychological wellbeing, quality of life and care for own health $(p<0.001)$. COVID-19 restrictions in SLO worsened psychological wellbeing and quality of life $(p<0.001)$, but increased care for own health $(p=0.005)$. Differences in the magnitude of change between the countries were found in general health $(p<0.001)$ and fitness levels $(p<0.001)$, which decreased only in ITA, while psychological wellbeing $(p<0.001)$ and quality of life $(p<0.001)$ decreased more in ITA than in SLO.

Additionally, we analysed a subsample of 548 participants who used body mass scale regularly and quantitatively reported changes of body mass in the range of -7 to $+7 \mathrm{~kg}$ with an average increase of $0.27 \pm 2.02 \mathrm{~kg}$ where a multiple linear regression explained $22 \%(R=0.470$; $p<0.001$ ) of body mass change variance through seven predictors (Table 2). Increase of meal sizes, unhealthy food consumption, psychological wellbeing, age, and physical inactivity positively contributed to body mass gains, while general health and care for own health contributed negatively to body mass gains.

\section{Discussion}

The current paper represents an upgrade of the crosssectional cohort study ELP-COVID-19 survey [3] conducted among 4108 participants from nine European countries. It compares two countries, SLO and ITA, with different restrictive measures and very different epidemiological outcomes of the COVID-19 pandemic [3].

We confirmed that the restrictive COVID-19 pandemic measures in the $1^{\text {st }}$ wave that lasted about two months (SLO: from March 12 to May 4, 2020; ITA: from March 8 to May 4, 2020) with associated higher daily new cases and deaths in ITA had a grater impact on ITA than SLO. From the World Health Organization Coronavirus Disease (COVID-19) dashboard [7] and Fig. 1 it is evident that in the period of the active online survey, from April 15 to 282020 ITA had more COVID-19 cases, rose from 162,488 to 199,414 cases, 


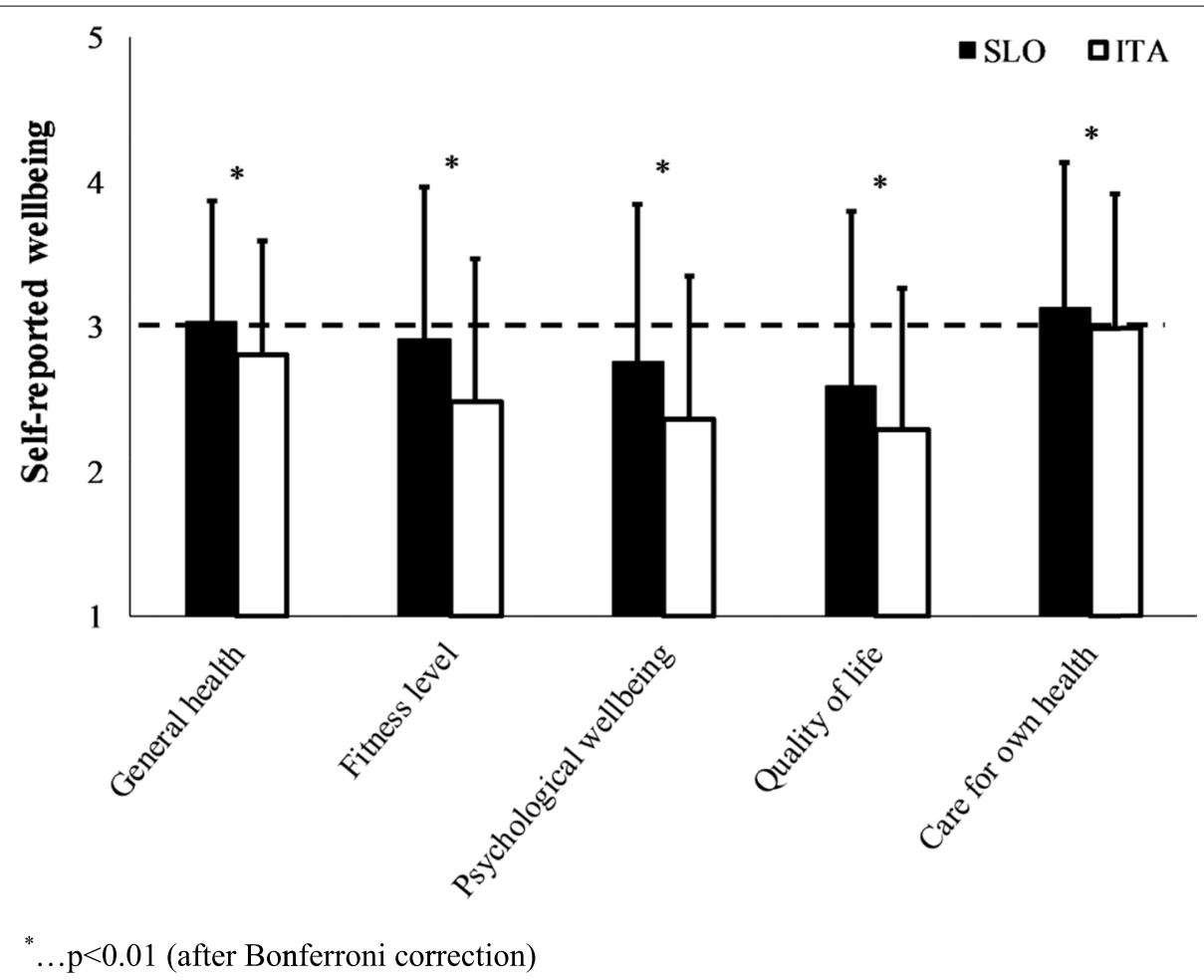

Fig. 4 Likert scale values of self-reported wellbeing changes (increases/better $>3$ or decreases/worse $<3$ ) during COVID-19 restrictions in Slovenia (SLO) and Italy (ITA)

Table 2 A multiple linear regression of body mass increase during COVID-19

\begin{tabular}{lllllll}
\hline Predictor & B & $\boldsymbol{\beta}$ & $\boldsymbol{p}$ & & Partial R & VIF \\
\hline Constant & -5.470 & \multicolumn{5}{c}{0.283} \\
Meal sizes & 0.492 & 0.226 & $<0.001$ & 0.234 & 1.15 \\
Unhealthy food & 0.251 & 0.160 & $<0.001$ & 0.167 & 1.15 \\
General health & -0.399 & -0.165 & 0.001 & -0.141 & 1.72 \\
Psychological wellbeing & 0.224 & 0.116 & 0.014 & 0.108 & 1.45 \\
Care for own health & -0.381 & -0.183 & $<0.001$ & -0.167 & 1.51 \\
Age & 0.010 & 0.076 & 0.047 & 0.084 & 1.03 \\
Changes in physical inactivity & 0.001 & 0.065 & 0.058 & 0.071 & 1.08 \\
\hline
\end{tabular}

Dependent variable: body mass change from before to during COVID-19 pandemics; B...regression coefficient; $\beta$... standardised regression coefficient; Partial R...partial correlation coefficient, VIF Variance inflation factor

than in SLO, rose from 1,220 to 1,407 cases. A similar difference was observed in COVID-19 related deaths, where in ITA they rose from 21,069 to 26,977 (an increase of 5,908 deaths) and in SLO from 56 to 83 (an increase of 27). On April 28 2020, COVID-19 prevalence among the population was $3.3 \%$ in ITA and $0.06 \%$ among SLO residents [7]. At the same time we found that this affected everyday life practices in the ITA population more than in the SLO population. COVID19 related changes were greatest in PA domains (physical inactivity, walking, recreational sports, and physical work).

Increases in physical inactivity and decreases in walking time, recreation time and physical work in ITA were highly variable (37-80\%) and greater compared with SLO (from no change to 58\%). Due to differences in age and sex distribution between the samples of ITA and SLO (younger population and more females in ITA compared to SLO), we obtained BDC differences between both countries, showing lower physical inactivity in ITA and higher walking time and recreation time in ITA than in SLO. However, these differences were statistically included in the analysis as a covariance to confirm a higher impact in ITA than in SLO. Nonetheless, these BDC differences yielded even more relevant effects of COVID-19 restrictions in ITA than in SLO. Moreover, self-reported general health and fitness levels declined only in ITA, whereas psychological well-being and quality of life declined in both countries. Concern about own health increased only in SLO.

At the first glance COVID-19 consequences in SLO were mitigated most likely due to lower absolute or per capita numbers of new COVID-19 cases and deaths. 
This is supported by a comparison of restrictive measures, which were similar in both countries. The difference is that in ITA the first major restriction was initiated 38 days after the first COVID-19 case while in SLO only 8 days after the first COVID-19 case. However, SLO also experienced milder COVID-19 pandemic restrictions limiting outdoor movement [6].

When comparing ITA and SLO consequences in the PA domain with pooled data from nine European countries [3], we found a higher increase in physical inactivity in ITA $(65 \%)$ than in the pooled countries $(50 \%)$ and lower in SLO (21\%). Walking time decreased more in ITA (69\%) than in the pooled countries (21\%) and in SLO (4.4\%). Recreational time also decreased more in ITA (37\%) compared to the pooled countries $(24 \%)$ while in SLO this increased (9.7\%). Interestingly, while physical work remained unchanged in ITA, it increased in the pooled countries (37\%), similarly to the case in SLO (38\%). This can be explained by the differences in the ITA sample, as the younger population is not as involved in physical work activities (e.g., gardening) compared to the Slovenian sample, where the older population was more involved in domestic or external physical work typical of spring [3]. A study [4] using the International Physical Activity Questionnaire Short Form (IPAQ-short) [22] in 22 countries reported similar changes in increasing sitting time (28.6\%), decrease of walking (34\%) and moderate and vigorous PA decreased by $33 \%$. It is evident also in our study that changes in PA in ITA were significantly greater than in SLO and greater than in the aforementioned study of 22 countries, as reported in the literature $[3,4]$.

There was an impact of COVID-19 restrictions on eating habits, resulting in an equal increase of body mass in both countries. Twenty-two percent of the variance in body mass gain was explained by larger meal sizes (seen only in ITA), participant's age, increased physical inactivity (seen in both countries), lower self-perception of general health status (seen only in ITA), increased self-perception of psychological wellbeing (seen in both countries), lower self-perception of care for health (increased only in SLO) and increased unhealthy food intake, although on average this did not change in SLO and ITA. We could speculate that physical inactivity, increased meal sizes, age, and psychological wellbeing could have a causal relationship with body mass gains and general health status with own health care a consequential relationship with body mass gains. Diminished work duties, home confinement, self-scheduling, increased screen time $[1,23]$ along with stockpiling of food led to increased psychological wellbeing, which in turn may have induced overeating and consequent unbalanced energy intake [24, 25]. Whereas among lifestyle characteristics, regular exercise seems to be the most important independent predictor for a perceived overall health-related quality of life $[26,27]$, on the other hand a low self-image after drastically increased physical inactivity and body mass gain could explain decreased self-perception of general health status and care for own health [28].

Nevertheless, a "positive" COVID-19 consequence was in decreased alcohol consumption as was seen in other studies [7], however, larger changes were found in ITA than in SLO; smoking, on the other hand, decreased only in ITA. This could be explained by the measures of home confinement and restricted access to public spaces, which reduces social life and the accompanying social habits such as drinking and smoking, that are normally associated with the population of young people who was more represented in ITA sample.

\section{Conclusions}

Our study presents the consequences in some healthrelated daily practices (PA and dietary habits) of different restriction measures in two neighbouring countries with very different numbers of COVID-19 cases and deaths. Although the restrictions were not drastically different, they had a great effect on what differences occurred between two countries. The smaller differences in everyday life practices were more beneficial to SLO, as ITA population experienced $44 \%$ greater increases in physical inactivity, a $64 \%$ greater decrease in walking time, a $47 \%$ greater decrease in recreation time, and did the same amount of physical work as before Covid19 restrictions, whereas in SLO it increased by $38 \%$. As the present study highlights the consequences of the two different COVID-19 pandemic scenarios on people's everyday lives, especially of those that are important for ensuring health, both health related habits, PA and eating habits, and also health risk behaviour (alcohol consumption and smoking) were included in the protocol. The consequences found in our study were previously linked to chronic diseases such as obesity, diabetes, cardiovascular diseases, cancer and others [7, 24], which were also linked to higher mortality rates in COVID-19 patients [29]. Therefore, when setting limits between outbreaks or waves of COVID-19, governments should be aware of the harmfulness of limiting health determinants as a direct consequence of COVID-19 restrictions. Measures and restrictions should be based on scientific grounds and professional guidelines, otherwise even more serious consequences and outcomes can be expected in the event of a recurrence of the disease or the onset of a different one. 


\begin{abstract}
Abbreviations
BDC: before COVID-19 pandemic;"ELP COVID-19" consortium: Consortium of six partners from Science and Research Centre Koper (Slovenia), Faculties of sport, University of Novi Sad (Serbia), University of Palermo (Italy), University of Zagreb (Croatia), University of Prešov (Slovakia), University of Cadiz (Spain): GDP: General Data Protection Regulation; ITA: Italy; SLO: Slovenia; WHO: the World Health Organisation.
\end{abstract}

\section{Acknowledgements}

We would like to thank the "ELP COVID-19" consortium for conducting the online survey and all anonymous respondents who participated in the study.

\section{Authors' contributions}

All authors were engaged in the investigation (survey examination). SP and BŠ made a concept of the article, BŠ, SP and AG analysed the data. BŠ; SP, AG and $A B$ participated in the interpretation of the data in the work. GLC, RP, PD, IM made the revision of work critically and add important intellectual content. All authors read and approved the final manuscript.

\section{Funding}

The study was financed by the authors' institutions: Science and Research Centre Koper, Slovenia, Research program (P5-0381) Kinesiology for quality of life.

\section{Availability of data and materials}

The datasets used and/or analysed during the current study are available from the corresponding author on reasonable request.

\section{Declarations}

\section{Ethics approval and consent to participate}

The presented study of "Differences of Slovenian and Italian daily practices experienced in the first wave of COID-19 pandemic" represents a part of a larger international collaboration between an international group of researchers in the online survey "Everyday practices in the COVID -19 period" conducted in 7 European countries. As the survey also investigated the experience of distress during COVID -19, the Ethics Committee-commission of the Faculty of Sport and Physical Education, approved this study under Decision No. 46-06-02/20.

Informed consent was obtained from all subjects. Explanation: The study itself did not carry any risk of violating ethical principles because participation in the online survey was voluntary. When participants clicked on the link of the survey, they received an invitation familiarizing them with the aim and scope of the survey and informing them that data collection and analysis would be carried out in accordance with the General Data Protection Regulation (GDPR) By clicking on the link to participate in the survey, participants were deemed to have consented to participate, yet participants were free to opt out at any time.

All methods were carried out according to relevant guidelines and regulation.

\section{Consent for publication}

Not applicable.

\section{Competing interests}

The authors declare that they have no competing interests.

\section{Author details}

${ }^{1}$ Institute for Kinesiology Research, Science and Research Centre Koper, Koper, Slovenia. ${ }^{2}$ Department of Psychology, Educational Science and Human Movement, Università Degli Studi Di Palermo, Palermo, Italy. ${ }^{3}$ Faculty of Sport and Physical Education, University of Novi Sad, Novi Sad, Serbia.

Received: 18 May 2021 Accepted: 24 January 2022

Published online: 16 February 2022

\section{References}

1. Shove E, Trentmann F, Wilk RR, editors. Time, consumption and everyday life: practice, materiality and culture. Oxford ; New York: Berg; 2009. p. 236 (Cultures of consumption series).
2. Wilk R. The edge of agency: routines, habits and volition. In: Time, consumption and everyday life. Oxford: Routledge; 2009. pp. 143-154. Available on: https://d1wqtxts1xzle7.cloudfront.net/30231393/20100 824114612991-with-cover-page-v2.pdf?Expires=1643716033\&Signa ture $=$ HSX1Q7vAwYtG7QkrNu1wcG8IFLXyuOPReEbA8kZfZTSkki4014 HqR8-1C9nShJW8Ixb91hvNajK3KZ9DBqjNT7SQFUPSkMrHGvDZcr9CL QQ2XWR1gA2 AQBUCazZHRFVJKKzD5LU5TXwd3bm0hilGFRbYP4UQtfz EoMMH2bOqWgZ1aPOugSyzvOKUKGW6Kk-RoBQYu6Zd07nsD9j67Dq 07326qwgEbmvCFdLDvsG5Lb9lev03FRn4Qv7626aaW0qVpHRCNblgbN y7JvQGCKPto-G6Vtb8UhCZCToByp6cqRHw5bjuNak8Tqo5FZyrw9G7dBF xZjGvtwwuQ5krAw_\&Key-Pair-Id=APKAJLOHF5GGSLRBV4ZA\#page= 158.

3. Pišot S, Milovanović I, Šimunič B, Gentile A, Bosnar K, Prot F, et al. Maintaining everyday life praxis in the time of COVID-19 pandemic measures (ELP-COVID-19 survey). Eur J Public Health. 2020 Dec 11 [cited 2021 May 18];30(6):1181-6. Available from: https://academic.oup.com/eurpub/artic le/30/6/1181/5880552

4. Ammar A, Brach M, Trabelsi K, Chtourou H, Boukhris O, Masmoudi L, et al. Effects of COVID-19 Home Confinement on Eating Behaviour and Physical Activity: Results of the ECLB-COVID19 International Online Survey. Nutrients. 2020 May 28 [cited 2020 Nov 2];12(6):1583. Available from: https://www.mdpi.com/2072-6643/12/6/1583

5. Italian Government Official Website. Available from: http://www.governo. it/it/coronavirus-misure-del-governo.

6. Slovenian Government Official Website. [cited 2020 Aug 31]. Available from: www.gov.si/teme/koronavirus/vladni-ukrepi/

7. WHO Coronavirus Disease (COVID-19) Dashboard. [cited 2020 Aug 25]. Available from: https://covid19.who.int/table

8. Thiel DM, Sayah FA, Vallance J, Johnson ST, Johnson JA. Physical Activity and Health-Related Quality of Life in Adults With Type 2 Diabetes: Results From a Prospective Cohort Study. J Phys Act Health. 2017;14(5):368-74. Available from: https://journals.humankinetics.com/view/journals/jpah/ 14/5/article-p368.xml.

9. Sidor A, Rzymski P. Dietary Choices and Habits during COVID-19 Lockdown: Experience from Poland. Nutrients. 2020;12(6):1657. Available from: https://www.mdpi.com/2072-6643/12/6/1657.

10. Vanderbruggen $N$, Matthys F, Van Laere S, Zeeuws D, Santermans L, Van den Ameele S, et al. Self-Reported Alcohol, Tobacco, and Cannabis Use during COVID-19 Lockdown Measures: Results from a Web-Based Survey. Eur Addict Res. 2020;26(6):309-15.

11. Acree LS, Longfors J, Fjeldstad AS, Fjeldstad C, Schank B, Nickel KJ, et al. Physical activity is related to quality of life in older adults. Health Qual Life Outcomes. 2006;4(1):37. Available from: https://hqlo.biomedcentral.com/ articles/10.1186/1477-7525-4-37.

12. Gopinath B, Hardy LL, Baur LA, Burlutsky G, Mitchell P. Physical activity and sedentary behaviors and health-related quality of life in adolescents. Pediatrics. 2012;130(1):e167-74. Available from: http://pediatrics.aappu blications.org/cgi/doi/10.1542/peds.2011-3637.

13. Mitchell T, Barlow CE. Review of the role of exercise in improving quality of life in healthy individuals and in those with chronic diseases. Curr Sports Med Rep. 2011;10(4):211-6. Available from: http://journals.lww. com/00149619-201107000-00011.

14. Mishra SI, Scherer RW, Geigle PM, Berlanstein DR, Topaloglu O, Gotay CC, et al. Exercise interventions on health-related quality of life for cancer survivors. Cochrane Gynaecological, Neuro-oncology and Orphan Cancer Group, editor. Cochrane Database Syst Rev. 2012. [cited 2021 May 18]; Available from: http://doi.wiley.com/https://doi.org/10.1002/14651858. CD007566.pub2

15. Florez H, Pan Q, Ackermann RT, Marrero DG, Barrett-Connor E, Delahanty $\mathrm{L}$, et al. Impact of Lifestyle Intervention and Metformin on Health-Related Quality of Life: the Diabetes Prevention Program Randomized Trial. J Gen Intern Med. 2012;27(12):1594-601. Available from: http://link.springer. com/10.1007/s11606-012-2122-5.

16. BDA. Eating well during Coronavirus / COVID-19. [cited 2021 Dec 11]. Available from: https://www.bda.uk.com/resource/eating-well-duringcoronavirus-covid-19.html

17. Hill JO, Wyatt HR, Peters JC. Energy Balance and Obesity. Circulation. 2012;126(1):126-32. Available from: https://www.ahajournals.org/doi/10. 1161/CIRCULATIONAHA.111.087213.

18. Lo Coco G, Gentile A, Bosnar K, Milovanović I, Bianco A, Drid P, et al. A Cross-Country Examination on the Fear of COVID-19 and the Sense of 
Loneliness during the First Wave of COVID-19 Outbreak. Int J Environ Res Public Health. 2021;18(5):2586. Available from: https://www.mdpi.com/ $1660-4601 / 18 / 5 / 2586$

19 Rosenbaum S, Ward P, International working G. The simple physical activity questionnaire. Lancet Psychiatry. 2016;3(1):e1.

20. National Institute for Public Health in Slovenia. Evropska anketa o zdravju in zdravstvenem varstvu / European Health Interview Survey (EHIS). 2007. ADP - IDNo: EHIS07. https://doi.org/10.17898/ADP_EHIS07_V1.

21. Hotelling $H$. The generalization of Student's ratio. In: Breakthroughs in statistics. New York: Springer; 1992. p. 54-65.

22 Craig C, Marshall AL, Sjostrom M. International physical activity questionnaire: 12-country reliability and validity. Med Sci Sports Exer. 2003;35(8):1381-95.

23. Galali Y. The impact of COVID-19 confinement on the eating habits and lifestyle changes: a cross sectional study. Food Sci Nutr. 2021;9(4):210513. Available from: https://onlinelibrary.wiley.com/doi/10.1002/fsn3.2179.

24. Sánchez-Sánchez E, Ramírez-Vargas G, Avellaneda-López Y, OrellanaPecino Jl, García-Marín E, Díaz-Jimenez J. Eating Habits and Physical Activity of the Spanish Population during the COVID-19 Pandemic Period. Nutrients. 2020:12(9):2826. Available from:https://www.mdpi.com/2072$6643 / 12 / 9 / 2826$.

25. Martinez-Ferran M, de la Guía-Galipienso F, Sanchis-Gomar F, ParejaGaleano H. Metabolic Impacts of Confinement during the COVID-19 Pandemic Due to Modified Diet and Physical Activity Habits. Nutrients. 2020;12(6):1549. Available from: https://www.mdpi.com/2072-6643/12/6/ 1549

26. Petek D, Petek-Ster M, Tusek-Bunc K. Health behavior and health-related quality of life in patients with a high risk of cardiovascular disease. Slov J Public Health. 2018;57(1):39-46. Available from: https://www.sciendo. com/article/10.2478/sjph-2018-0006.

27. Dwyer MJ, Pasini M, De Dominicis S, Righi E. Physical activity: benefits and challenges during the covid-19 pandemic. Scand J Med Sci Sports. 2020;30(7):1291-4. Available from: https://onlinelibrary.wiley.com/doi/ abs/10.1111/sms.13710

28. López-Bueno R, Calatayud J, Casaña J, Casajús JA, Smith L, Tully MA, et al. COVID-19 confinement and health risk behaviors in spain. Front Psychol. 2020;11:1426. Available from: https://www.frontiersin.org/article/10.3389/ fpsyg.2020.01426/full.

29. Huang C, Wang Y, Li X, Ren L, Zhao J, Hu Y, et al. Clinical features of patients infected with 2019 novel coronavirus in Wuhan, China. The Lancet. 2020;395(10223):497-506. Available from: https://linkinghub.elsev ier.com/retrieve/pii/S0140673620301835.

\section{Publisher's Note}

Springer Nature remains neutral with regard to jurisdictional claims in published maps and institutional affiliations.

Ready to submit your research? Choose BMC and benefit from:

- fast, convenient online submission

- thorough peer review by experienced researchers in your field

- rapid publication on acceptance

- support for research data, including large and complex data types

- gold Open Access which fosters wider collaboration and increased citations

- maximum visibility for your research: over $100 \mathrm{M}$ website views per year

At BMC, research is always in progress.

Learn more biomedcentral.com/submissions 